\title{
Multi-scale variability of the sea surface temperature in the Tropical Atlantic
}

\author{
Rita Valéria Andreoli and Mary Toshie Kayano \\ Centro de Previsão do Tempo e Estudos Climáticos, Instituto Nacional de Pesquisas, Espaciais, São José dos Campos, \\ São Paulo, Brazil \\ Received 21 November 2003; revised 21 November 2003; accepted 12 March 2004; published 5 May 2004.
}

[1] Tropical Atlantic (TA) sea surface temperature (SST) variability is studied using the Continuous Wavelet Transform (CWT) of the SST indices in the Tropical North Atlantic (TNA), Tropical South Atlantic (TSA), and Equatorial Atlantic (EQA). CWT of the difference index (TNSD) between the TNA and TSA indices and the cross-wavelet spectrum for the TNA and TSA indices are also examined. The analyses focus the shortinterannual, interannual, and decadal scales. The Global Wavelet Power of the TNA, TSA, and EQA indices confirm previous findings on the dominant scales of the SST variability in different TA sectors. The decadal peaks are dominant for the TNA and TSA indices while the interannual peaks are significant only for the EQA index. The scale averaged $\Delta \Phi$ series for all scales feature a number of abrupt reversals of $\pm 180^{\circ}$ which depends on the scale, with larger number for smaller scales. The $\Delta \Phi$ during the period between two subsequent abrupt reversals remains close to $\pm 180^{\circ}$ or varies within sub-intervals of the $-180^{\circ}$ to $+180^{\circ}$ range, thus the dipole-like, cross-equatorial SST anomaly gradient, monopole, and equatorial patterns are established as evolving modes. For all scales, the periods of abrupt $\Delta \Phi$ reversals of $\pm 180^{\circ}$ occur within the periods with change in the meridional propagation directions of the SST anomalies or with reduced SST anomalies. This result strongly suggests that the establishment of the SST anomaly patterns in the TA depends crucially on the meridional propagation of the SST anomalies. This is a new aspect not discussed before. INDEX TERMS: 4215 Oceanography: General: Climate and interannual variability (3309); 3309 Meteorology and Atmospheric Dynamics: Climatology (1620); 1635 Global Change: Oceans (4203); 4572 Oceanography: Physical: Upper ocean processes; KEYWORDS: wavelet, sea surface temperature, tropical Atlantic

Citation: Andreoli, R. V., and M. T. Kayano (2004), Multi-scale variability of the sea surface temperature in the Tropical Atlantic, J. Geophys. Res., 109, C05009, doi:10.1029/2003JC002220.

\section{Introduction}

[2] Several aspects of the short interannual to decadal variability of the sea surface temperature (SST) in the Tropical Atlantic (TA) received considerable attention during the last 10 years. In this context, studies conducted independently by Zebiak [1993] and Wagner and da Silva [1994] showed that a significant part of the observed SST interannual variability in the TA is related to an internal Atlantic equatorial mode similar to the El Niño/Southern Oscillation (ENSO) in the Pacific. The Atlantic equatorial mode features a SST pattern roughly symmetric about the equator in the eastern side of the basin and varies in a timescale of $2-5$ years. Since this mode is not strong enough to determine the total interannual variability in $\mathrm{TA}$, other dynamically distinct and external (or remotely) forced modes might contribute to this variability [Zebiak, 1993]. Among these modes, the externally forced ENSO mode manifests in the Tropical North Atlantic (TNA) and

Copyright 2004 by the American Geophysical Union. 0148-0227/04/2003JC002220\$09.00 contains strong interannual variability [e.g., Enfield and Mayer, 1997; Saravanan and Chang, 2000]. On the other hand, several authors refer to another internal Atlantic mode displaying anti-symmetric SST anomaly pattern about the equator, that relates to the interannual climate variations in northeast Brazil through the dynamics due to the air-sea interactions in the TA [e.g., Weare, 1977; Hastenrath, 1978; Moura and Shukla, 1981, Nobre and Shukla, 1996]. This second internal Atlantic SST mode has been interpreted as a dipole that, inducing an atmospheric response characterized by an anomalous thermally direct meridional circulation, affects the position and intensity of the Intertropical Convergence Zone (ITCZ), which in turn modulates the northeast Brazil rainfall variability [Moura and Shukla, 1981].

[3] However, there is still a debate on the existence of a SST dipole mode in the TA, hereinafter referred to as a dipole-like pattern. The fact that the observed and/or simulated SST anomaly time series representing the northern and southern poles of the dipole-like structure are uncorrelated leads several authors to suggest that the dominant lowfrequency (interannual to decadal) SST fluctuations in the TNA and Tropical South Atlantic (TSA) are not related each 
other [Houghton and Tourre, 1992; Mehta, 1998; Rajagopalan et al., 1998; Enfield et al., 1999; Dommenget and Latif, 2000]. Some authors showed that these fluctuations yield two modes, separated approximately by the ITCZ, with strong decadal component of distinct periodicity, on average, of 9.6 years for TNA and 14 years for TSA [e.g., Mélice and Servain, 2003]. Moreover, the decadal component of the SST index defined as the difference between the TNA and TSA SST anomaly indices has been attributed to coherent or strong decadal oscillations of the SST anomalies in either the TSA [Mehta and Delworth, 1995; Mehta, 1998] or TNA [Houghton and Tourre, 1992], but not in both. On the other hand, Enfield et al. [1999] made a distinction between the dipole-like pattern and cross-equatorial SST anomaly gradient mode and provided the statistics of their occurrences during the 1856-1991 period. They found that the dipole-like patterns occur only for $12-15 \%$ of the time and the cross-equatorial SST anomaly gradients, nearly half of the time. This result indicates that the SST dipole-like patterns in the TA seldom and randomly occur.

[4] In addition, Houghton and Tourre [1992] and Dommenget and Latif [2000], using observed and simulated SST data, suggested that dipole-like pattern results from the methodological constrains of the empirical orthogonal function (EOF) analysis. In the absence of a strong and well-organized signal in the TA, the EOF analysis will give a monopole for the first mode and two anti-symmetric poles in the second mode, and the rotated EOF analysis will yield two separate modes. Houghton and Tourre [1992] and Dommenget and Latif [2000], reproducing these expected results from the EOF analyses, argued against the occurrence of a dipole mode in the TA.

[5] The results above illustrate the complexity of the SST variability in the TA that in part might be explained by at least five modes: separated modes in the TNA and TSA, equatorial mode, dipole-like pattern, and cross-equatorial SST anomaly gradient mode. This paper will address the issues concerning the temporal dependence of the SST variability in the TA using time-frequency analyses. Therefore this work will be based on the Continuous Wavelet Transform (CWT) that is an appropriated technique to determine the dominant modes of variability and how these modes vary in time. Similar analyses done by Mélice and Servain [2003] emphasized aspects of the cross-equatorial SST anomaly gradient mode and were based on the 19641998 period. The present work aims to address further the time-frequency dependence of the short interannual to decadal variability of the SST anomalies in the TA for a longer period than that used by Mélice and Servain [2003]. This work explores also the aspects related to meridional propagations of the SST anomalies.

\section{Data and Methodology}

[6] The data used in this study consist of gridded monthly SST anomalies in the Atlantic Ocean between $37.5^{\circ} \mathrm{S}$ and $37.5^{\circ} \mathrm{N}$ (Tropical Atlantic, TA) during the $1856-2000$ period. These data are on a $5^{\circ}$ by $5^{\circ}$ latitude-longitude resolution grid and were obtained by Kaplan et al. [1997] for the 1856-1991 period and are updated to 2000 using the available files available at http:// www.cdc.noaa.gov.
[7] Monthly SST anomaly indices for the 145 years are defined to investigate the SST variations in several areas of the TA: (1) TNA index refers to area averaged SST anomalies in the region limited at $7.5^{\circ} \mathrm{N}, 22.5^{\circ} \mathrm{N}, 52.5^{\circ} \mathrm{W}$, and $22.5^{\circ} \mathrm{W}$; (2) TSA index refers to area averaged SST anomalies in the region limited at $22.5^{\circ} \mathrm{S}, 7.5^{\circ} \mathrm{S}, 17.5^{\circ} \mathrm{W}$, and $7.5^{\circ} \mathrm{E}$; (3) equatorial Atlantic (EQA) index refers to area averaged SST anomalies in the region limited at $7.5^{\circ} \mathrm{S}$, $7.5^{\circ} \mathrm{N}, 22.5^{\circ} \mathrm{W}$, and $12.5^{\circ} \mathrm{E}$; (4) difference index (TNSD index) refers to the difference between the TNA and TSA indices; and (5) zonal SST indices refer to longitude averaged SST anomalies for every $5^{\circ}$ in latitude in the TA.

[8] The TNA and TSA subsectors are approximately those used by Rajagopalan et al. [1998] in their study of the TA climate variability. The long-term linear trends contained in the SST indices are removed and the resulting series are standardized to allow comparisons for different indices.

[9] The Morlet wavelet is used for the time-frequency analyses. This wavelet is a complex exponential modulated by a Gaussian, $e^{i \omega_{o} \eta} e^{-\eta^{2} / 2}$, with $\eta=t / s$, where $t$ is the time, $s$ is the wavelet scale, and $\omega_{0}$ is a non-dimensional frequency. The computational procedure of the wavelet analysis described by Torrence and Compo [1998] (hereinafter TC98) is used. It is worth mentioning that the wavelet function at each scale $s$ is normalized by $s^{-1 / 2}$ to have unit energy, which ensures that the wavelet transform at each scale $\mathrm{s}$ is comparable to each other and to the transform of other time series (TC98).

[10] The relationship of the TNA and TSA indices is investigated by calculating their cross-wavelet spectrum and the wavelet coherency phase difference as proposed by Torrence and Webster [1999]. Given two time series $X(t)$ e $Y(t)$ with their wavelet transforms $W^{X}(t, s)$ and $W^{Y}(t, s)$, the cross-wavelet spectrum is defined as $W^{X Y}(t, s)=W^{X}(t, s)$ $W^{Y *}(t, s)$, where the asterisk is the complex conjugate. The wavelet squared coherency is defined as the squared modulus of the smoothed cross-wavelet spectrum, normalized by smoothed wavelet spectra,

$$
R^{2}(t, s)=\frac{\left|\left\langle s^{-1} W^{X Y}(t, s)\right\rangle\right|^{2}}{\left\langle s^{-1} W^{X}(t, s)\right\rangle\left\langle s^{-1} W^{Y}(t, s)\right\rangle},
$$

where brackets denote smoothing in both time and scale. The factor $s^{-1}$ is used to convert the squared wavelet coherency into an energy density. In addition, the wavelet coherency phase difference is given by

$$
\Delta \Phi(t, s)=\tan ^{-1} \frac{\Im m\left\{\left\langle s^{-1} W^{X Y}(t, s)\right\rangle\right\}}{\Re e\left\{\left\langle s^{-1} W^{X Y}(t, s)\right\rangle\right\}},
$$

where $(\Im m)$ and $(\Re e)$ are the imaginary and real parts of $W^{X Y}(t, s)$, respectively [Torrence and Webster, 1999].

[11] In order to get a better understanding of the shortinterannual to decadal variability of the SST in the TA, three scale-bands (year units) are selected: $1-2$ years (short-interannual), $2-5$ years (interannual), and $8-14$ years (decadal). Hereinafter, the scale-bands will be referred to as scales.

\section{Results}

\subsection{Independent Analyses for the TNA, TSA, and EQA Indices}

[12] The Global Wavelet Power (GWP) of the TNA, TSA, and EQA indices are shown in Figures $1 b, 2 b$, and $3 b$, respectively. These figures show strong 8 - to 14 -year 
a) Wavelet Power Spectrum - TNA

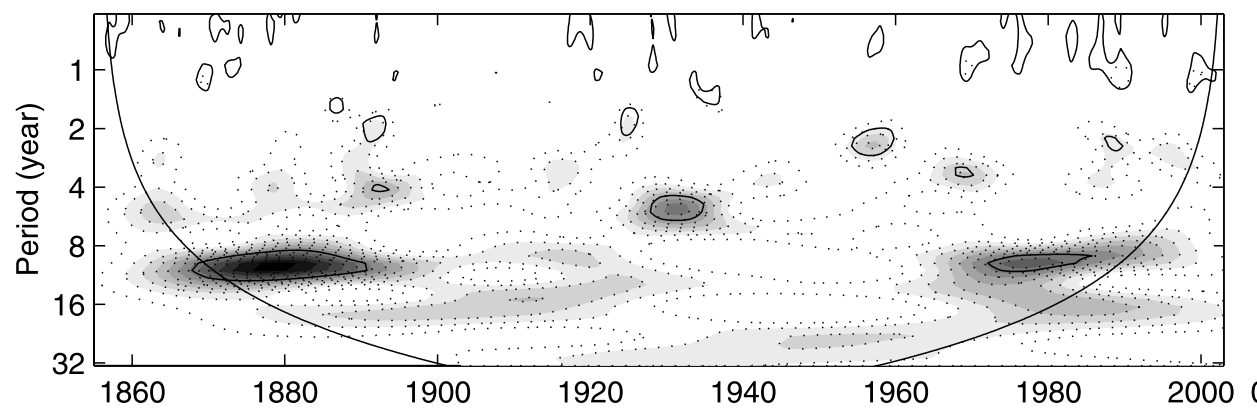

c) Average Variance b) Global Wavelet Power

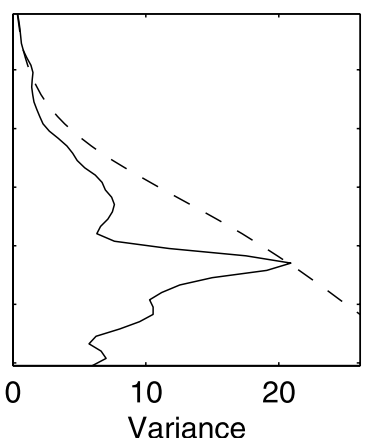

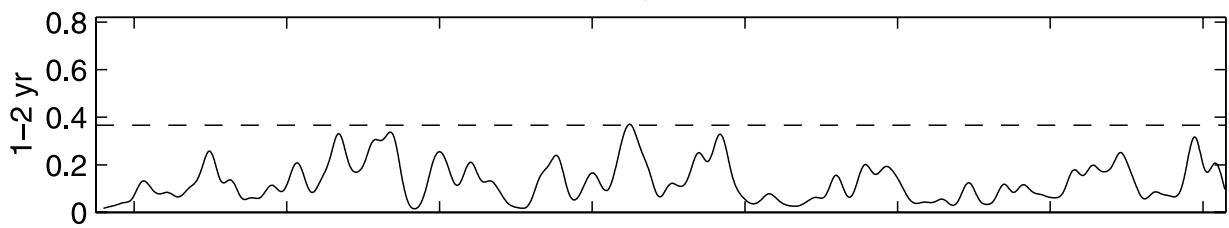
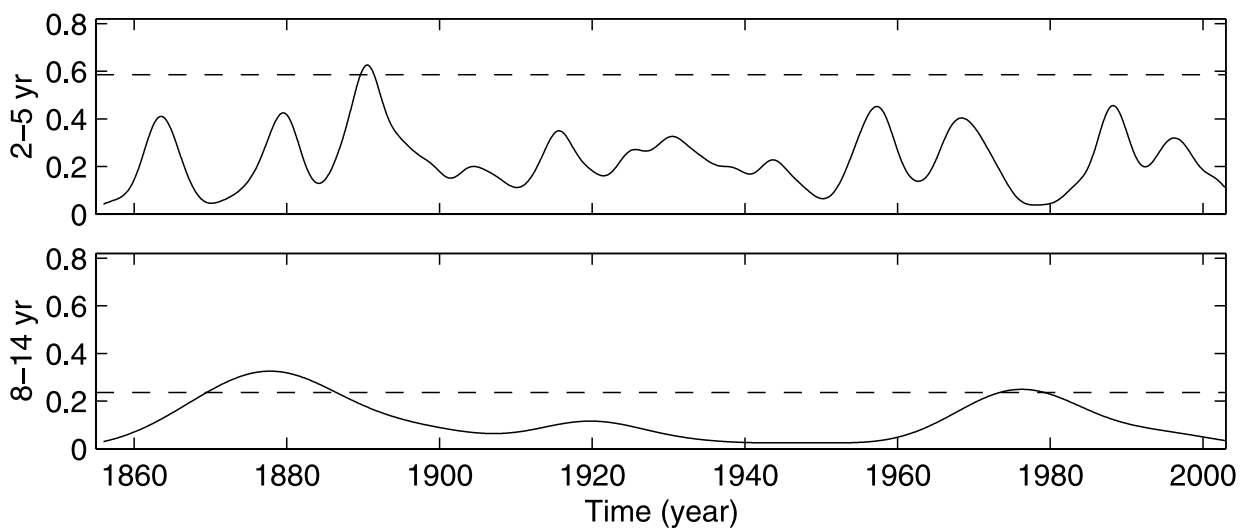

Figure 1. (a) Local wavelet power spectrum of the CWT of the TNA index normalized by $1 / \sigma^{2}\left(\sigma^{2}=\right.$ $0.12^{\circ} \mathrm{C}^{2}$ ); (b) Global Wavelet Power (GWP) (in variance units); and (c) Scale-Averaged wavelet Power (SAP) time series of the TNA index for 1- to 2-year, 2- to 5-year, and 8- to 14-year scales. The shaded contours in Figure 1a are at normalized variances varying from 5 to 60 with interval of 5 . The closed contours in Figure 1a encompass significant variances at 95\% confidence level and the region where the edge effects are important is under the U-shape curve in Figure 1a. The dashed curve in Figure 1b is the significance at 5\% level assuming a red-noise spectrum. The dashed line in Figure 1c indicates the minimum significant value at the $95 \%$ confidence level.

decadal peaks, which are significant at 5\% level for the TNA (peak at 9.8 years) and TSA (peak at 12.7 years) indices and are non-significant for the EQA index (peak at 12.7 years). The amplitude (in variance units) of the decadal GWP peak for the TSA index is larger than that for the TNA index (Figures $2 \mathrm{~b}$ and $1 \mathrm{~b}$ ). This is indicative of stronger decadal SST variability in the TSA than in the TNA, in agreement with previous findings [Mehta and Delworth, 1995]. The similarities between the GWP of the TSA and EQA indices suggest consistent SST variability in the TSA and EQA (Figures $2 \mathrm{~b}$ and $3 \mathrm{~b}$ ). In fact, these indices exhibit a non-significant secondary GWP peak approximately at 25 years (Figures $2 b$ and $3 b$ ) that is not evident for the GWP of TNA index (Figure 1b). In addition, the three indices show a secondary 2- to 5-year GWP peak that is significant at 5\% level for the EQA index at 2- to 2.5-year scale (peak at 3.5 years), and non-significant for the TSA (peak at 5.4 years) and TNA (peak at 4.9 years) indices.
[13] The wavelet power spectra (power or variance) for the three indices are displayed in time-period plots in Figures 1a, 2a, and 3a. The strong 8- to 14-year decadal peaks in the GWP of TNA, TSA and EQA indices are due to significant (at 5\% level) decadal variances observed during the periods $1870-1890$ and $1970-1985$ for TNA index, 1905-1925 and 1970-1985 for TSA index, and 1895-1915 for EQA index (Figures 1a, 2a, and 3a). Therefore, significant $(5 \%$ level $)$ decadal variances occur simultaneously for TNA and TSA indices during 19701985, and for the TSA and EQA indices during 1900-1915.

[14] On the other hand, the significant (at 5\% level) 1 - to 2-year and 2- to 5-year variances for all three indices occur during relatively short time intervals scattered in the 145 -year period (Figures 1a, 2a, and 3a). The numbers of these short time intervals and/or their extent increase relatively following the order from TNA, TSA, to EQA indices. This result indicates a dominance of the short-interannual and interan- 
a) Wavelet Power Spectrum - TSA

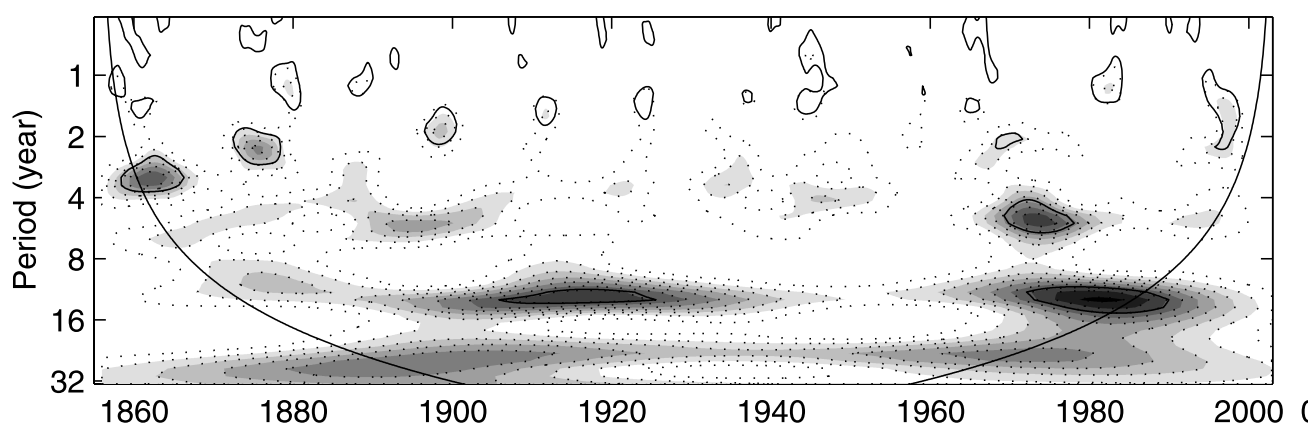

c) Average Variance b) Global Wavelet Power

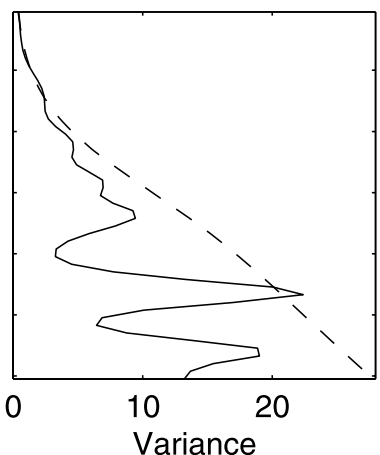

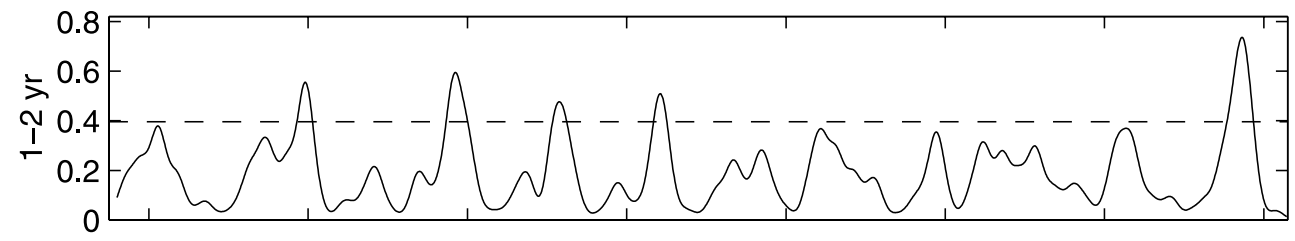
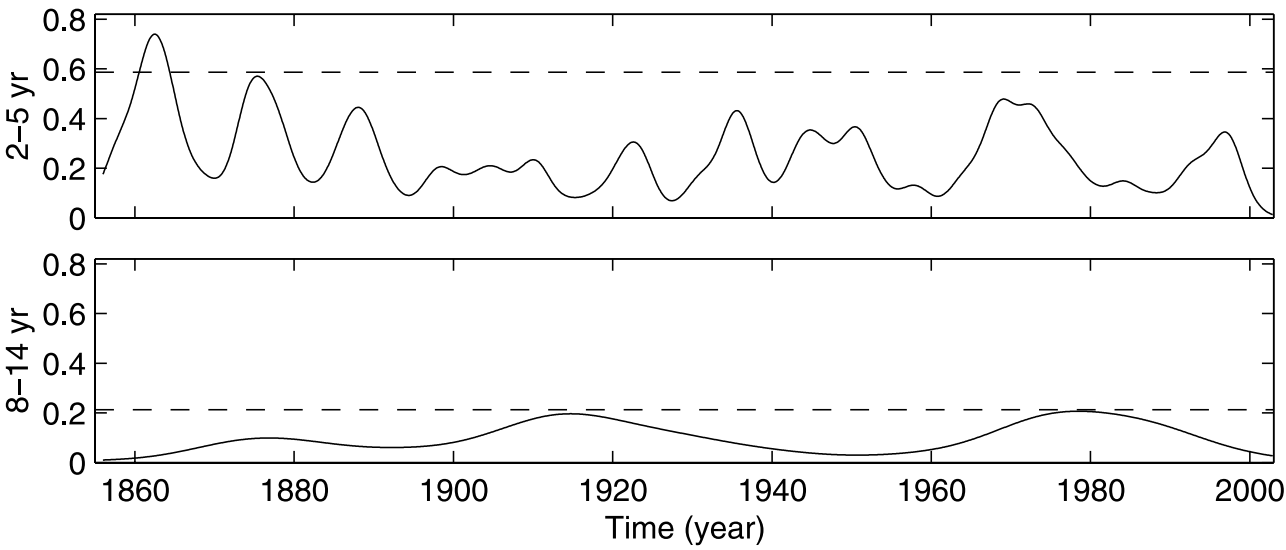

Figure 2. As in Figure 1, for the TSA index $\left(\sigma^{2}=0.12^{\circ} \mathrm{C}^{2}\right)$.

nual SST variability in the EQA, in accordance with previous results [e.g., Zebiak, 1993]. It is also noticeable that some periods with significant 1- to 2-year and 2- to 5-year variances for the EQA and TSA indices show overlapping, which suggests consistent SST variability in the EQA and TSA for these scales. It is also interesting to note significant (at 5\% level) 1- to 2-year variances for the TSA index manifesting approximately every 12 years during the $1890-1940$ period, when this index contains high significant decadal variances. This result suggests modulations of 1 - to 2-year scale variability by decadal scale variability.

[15] Scale Averaged wavelet Power (SAP) time series of the SST indices are constructed for 1- to 2-year, 2- to 5-year, and 8- to 14-year scales (Figures 1c, 2c, and 3c). The SAP is obtained from the equation (24) of TC98 and can be used to examine modulations of one time series by another or modulations of one scale by another within the same time series. The amplitudes (in variance units) of the time fluctuations of the SAP series of the TSA and EQA indices are relatively larger than those of the TNA index, in particular for 1- to 2-year and 2- to 5-year scales (Figures 1c, 2c, and 3c). In general, the SAP series of the TSA and EQA indices for 1- to 2-year and 2- to 5-year scales show quite similar time fluctuations with relatively larger amplitudes for the EQA index than for the TSA index. This reinforces the consistent SST variability for these scales in the EQA and TSA. On the other hand, the SAP series of the TNA index for 1- to 2-year and 2- to 5-year scales show mostly non-significant (at 5\% level) amplitudes. Regarding the SAP series for 8- to 14-year scale, quasi-significant (at 5\% level) values are noted for the TSA index during 1910-1930 and 1970-1982 and for the EQA index, during 1900-1910, and significant values for the TNA index during 1870-1890 and 1970-1985.

\subsection{Analysis for the TNSD Index}

[16] The GWP of the TNSD index shows significant (at $5 \%$ level) 8 - to 14-year decadal peak (maximum at 11.7 years) and two secondary non-significant peaks at 4.9 years and 25.5 years (Figure $4 \mathrm{~b}$ ). The strong 8 - to 14-year decadal component of the TNSD index is due to significant (at 5\% level) decadal variances during 18701890, 1915-1930, and 1965-1985 periods (Figure 4a), which overlap the periods with significant decadal variances, respectively, for the TNA index, TSA index, and for both TNA and TSA indices (Figures 1a and 2a). However, the significant decadal variances for TNA and TSA indices are due to different periodicities (9.8 years for TNA and 12.7 years for TSA). This suggests that the decadal fluctua- 
a) Wavelet Power Spectrum - EQA

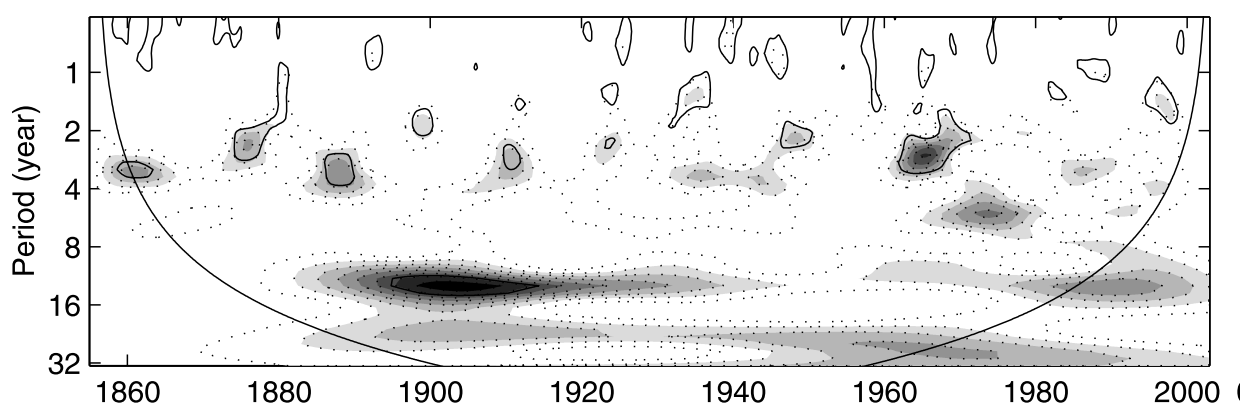

c) Average Variance
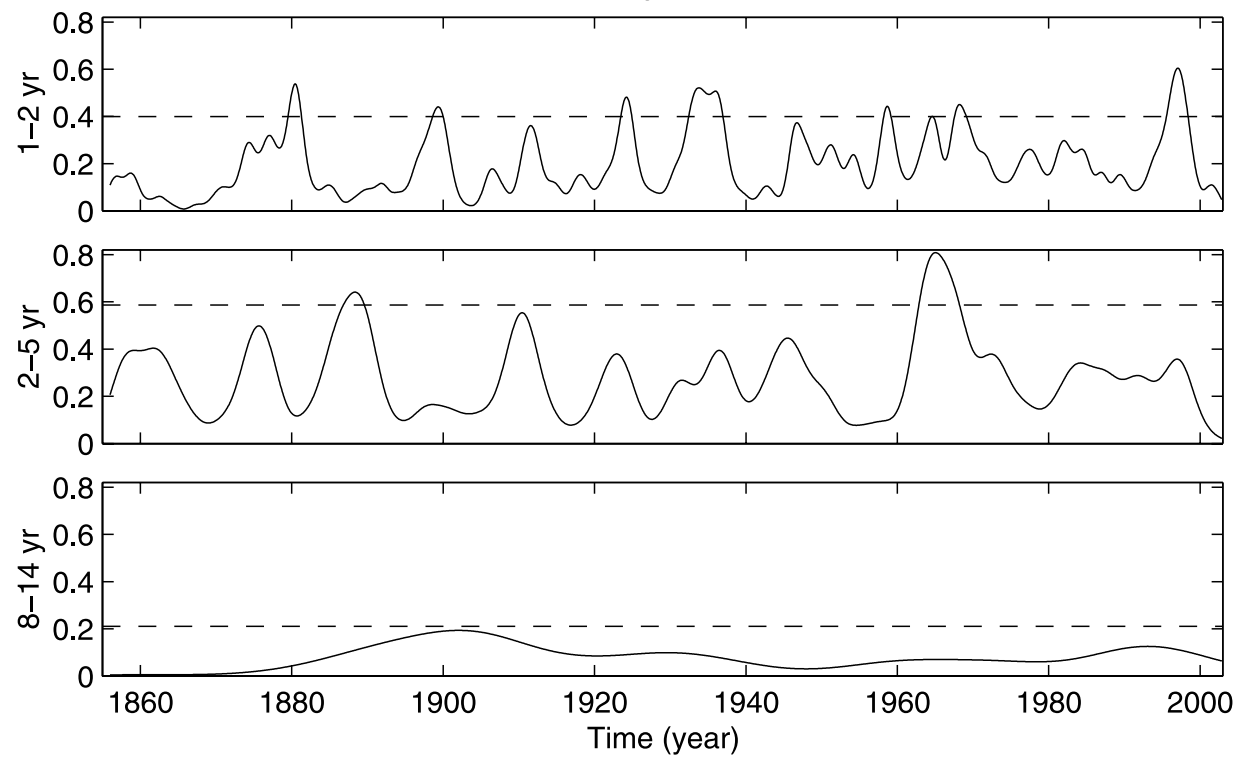

b) Global Wavelet Power

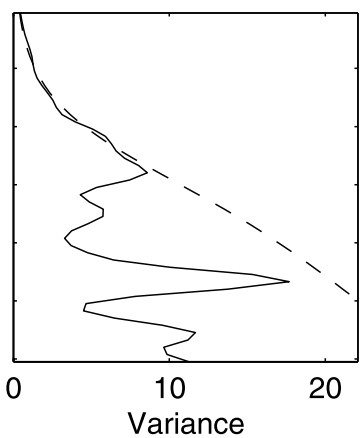

Figure 3. As in Figure 1, for the EQA index $\left(\sigma^{2}=0.12^{\circ} \mathrm{C}^{2}\right)$.

tions in the TNA and TSA indices might not be in phase and that the strongest decadal component of the TNSD index occurs when the TNA and TSA indices are out of phase. Most periods with significant 1- to 2-year and 2- to 5-year variances for the TNSD index overlap the periods with significant variances for these scales for either the TSA index or the TNA index.

[17] The SAP series of the TNSD index for 1- to 2-year, 2- to 5-year, and 8- to 14-year scales are displayed in Figure $4 \mathrm{c}$. Concerning the 1- to 2-year scale, the significant peaks $(5 \%$ level) of the SAP series of the TNSD index around 1900 and 1997 coincide with the significant peak of the SAP series of the TSA index, while the peaks approximately in 1937, 1960, and 1982 have no correspondence to significant values in the SAP of the TSA and TNA indices (Figures 1c, 2c, and 4c). The SAP series of the TNSD for 2-5 years shows quite regular fluctuations, in particular prior to 1900 , but without significant peaks. On the other hand, the significant (at 5\% level) peaks of the SAP series of the TNSD index for 8- to 14-year scale during 1870$1885,1912-1925$, and $1965-1990$ periods overlap, respectively, the periods for which significant 8- to 14-year decadal variances were noted for the TNA index, TSA index, and both indices.

[18] The above analyses showed significant variances for the TNSD, TNA, and TSA indices, for some periods and scales. It is worthwhile to call reader attention to the fact that the simultaneous occurrences of significant variances for the three indices does not necessarily imply the establishment of a dipole-like pattern or dynamical connections between the TNA and TSA. This aspect will be better clarified in the analysis of the phase difference between the TNA and TSA indices.

\subsection{Wavelet Coherency and Phase Difference Between the TNA and TSA Indices}

[19] The wavelet coherency between TNA and TSA indices is displayed in Figure 5. The prevailing low coherency between the TNA and TSA indices is indicative of the dominance of separated SST anomaly modes in the TNA and TSA for most scales and during the analyzed 145-year period. On the other hand, high coherency (exceeding 0.8) is evident for certain scale bands and periods (Figure 5). Examples of such periods and the corresponding approximate scales are 1856-1870 and 1915-1930 at 1- to 3-year scale, around the year 1890 at 2- to 3-year scale, 18561875 and 1930-1950 at 5- to 6-year scale, 1856-1890, $1920-1940$, and $1960-1975$ at 8- to 14-year scale, and 1940-2000 at 20- to 25-year scale. For these periods and scales the SST variations in the TSA and TNA can show strong interactions. In fact, the periods with high coherency at 8 - to 14-year decadal scale have correspondence to those 
a) Wavelet Power Spectrum - TNSD

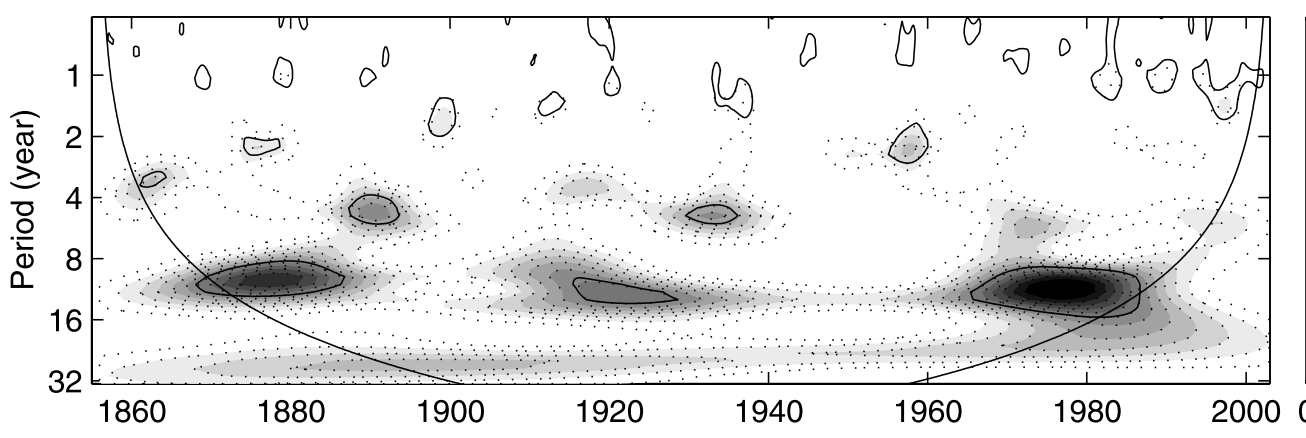

c) Average Variance b) Global Wavelet Power

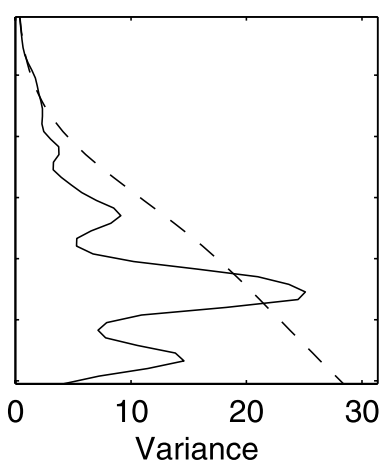

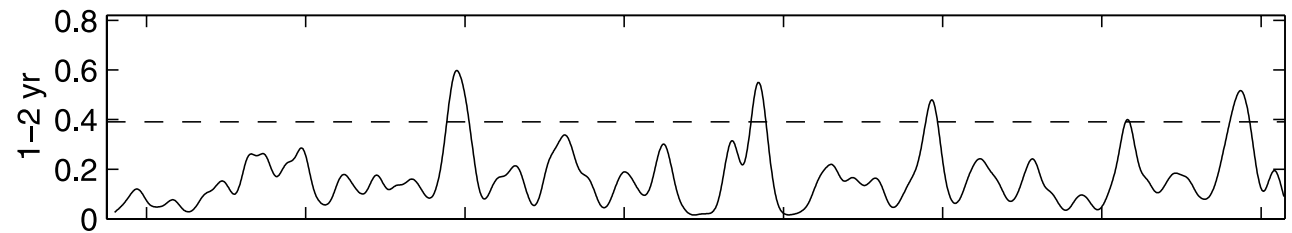
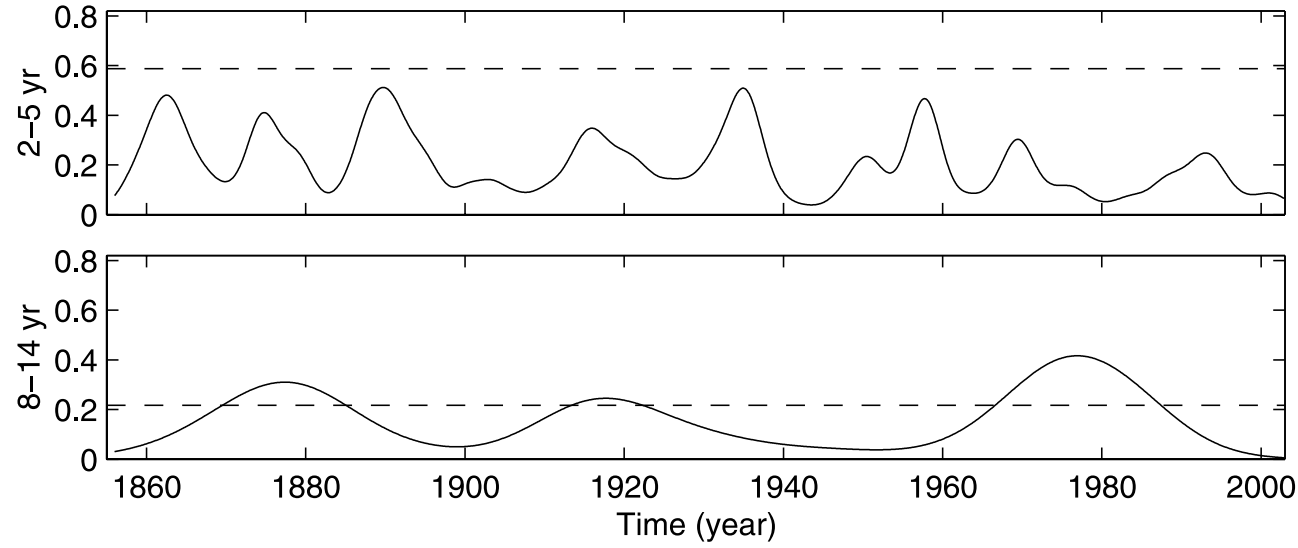

Figure 4. As in Figure 1, for the TNSD index $\left(\sigma^{2}=0.24^{\circ} \mathrm{C}^{2}\right)$.

for which significant decadal variances were noted for the TNSD index.

[20] The phase difference between the TNA and TSA indices $(\Delta \Phi)$ gives a better characterization of the SST anomaly patterns in the TA. The following approximated correspondences between $\Delta \Phi$ and the SST anomaly pattern are used: $\Delta \Phi= \pm 180^{\circ}$ corresponds to true dipole-like patterns; the $-90^{\circ} \leq \Delta \Phi \leq 90^{\circ}$ corresponds to monopole

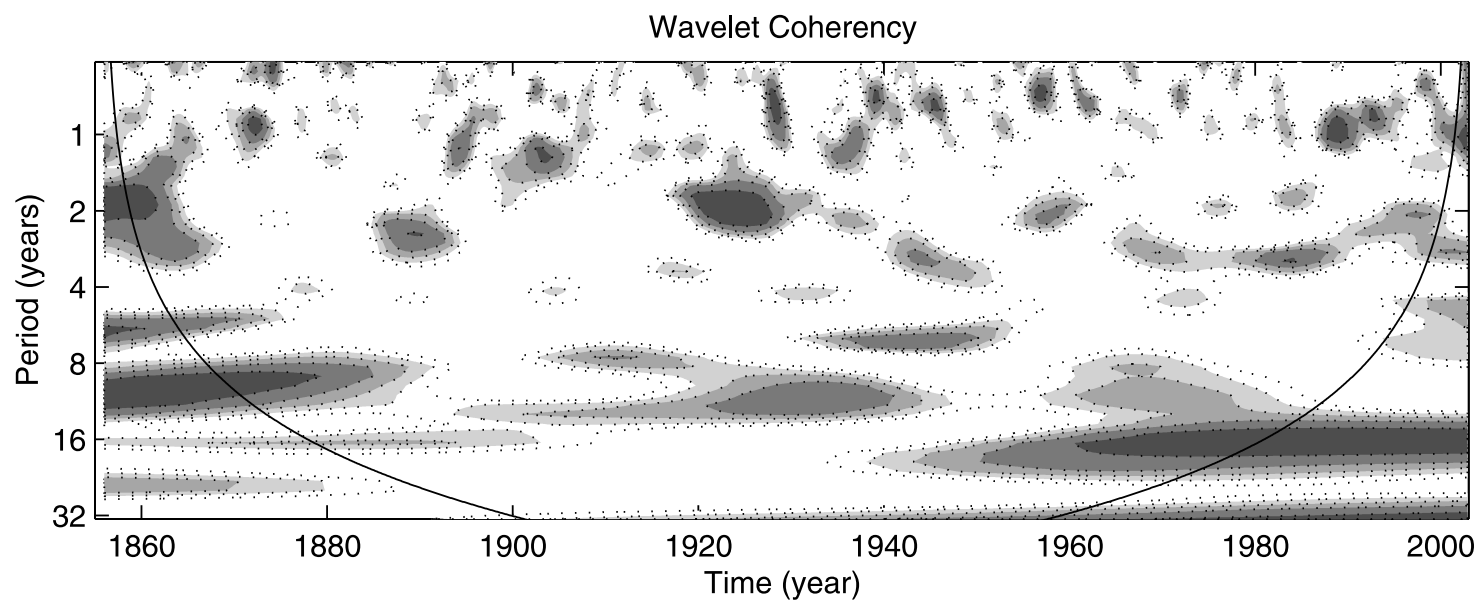

Figure 5. Wavelet coherency between the TNA and TSA indices. Contours are for wavelet squared coherency and vary from 0.5 to 1.0 with interval of 0.1 . The region where the edge effects are important is under the U-shape curve. 

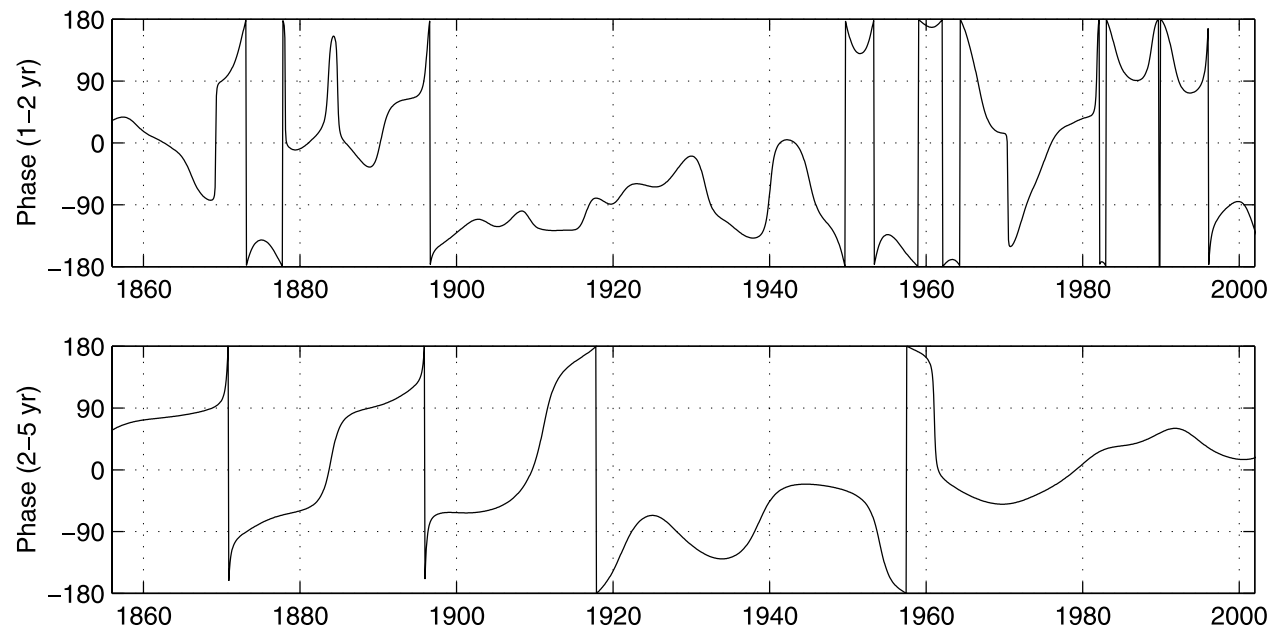

Figure 6. Instantaneous phase differences between the TNA and TSA indices averaged for 1- to 2-year and 2- to 5-year scales.

SST modes including the equatorial mode for $\Delta \Phi=0^{\circ}$; and the $-180^{\circ}<\Delta \Phi<-90^{\circ}$ and $+90^{\circ}<\Delta \Phi<+180^{\circ}$ correspond to cross-equatorial SST anomaly gradient modes. In order to facilitate interpretation, scale-averaged $\Delta \Phi$ series, as done by Mélice and Servain [2003] are used. In the case of the 8- to 14-year scale, additional scale-averaged $\Delta \Phi$ series for wavelet periods of $8.2,9$, 9.8, 10.7, 11.7, 12.7, and 13.9 years are also discussed.
[21] Regarding the 1- to 2-year scale, a number of abrupt (from one month to the subsequent one) $\Delta \Phi$ reversals of approximately $\pm 180^{\circ}$ are noted during $1870-1896$ and 1949-1996 periods (Figure 6). It is also noticeable that the shorter the time interval between two subsequent abrupt $\Delta \Phi$ reversals of $\pm 180^{\circ}(1873-1877,1949-1953,1953-$ $1959,1959-1962,1962-1964$, and 1982-1983), the closer $\Delta \Phi$ remains to $\pm 180^{\circ}$ (indicative of the cross-equatorial SST
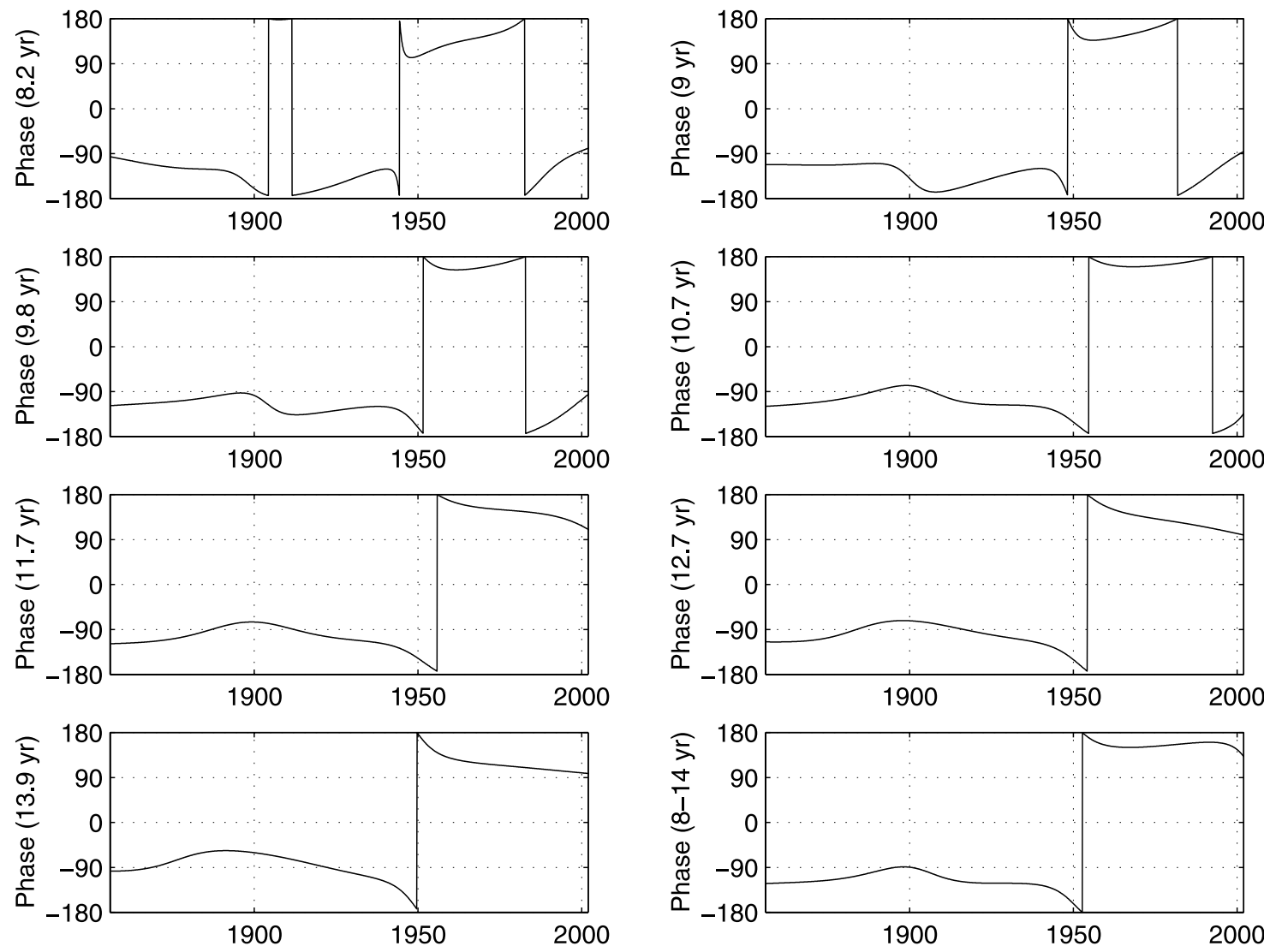

Figure 7. Instantaneous phase differences between the TNA and TSA indices averaged for 8.2-year, 9-year, 9.8-year, 10.7-year, 11.7-year, 12.7-year, 13.9-year, and 8- to 14-year scales. 
a)

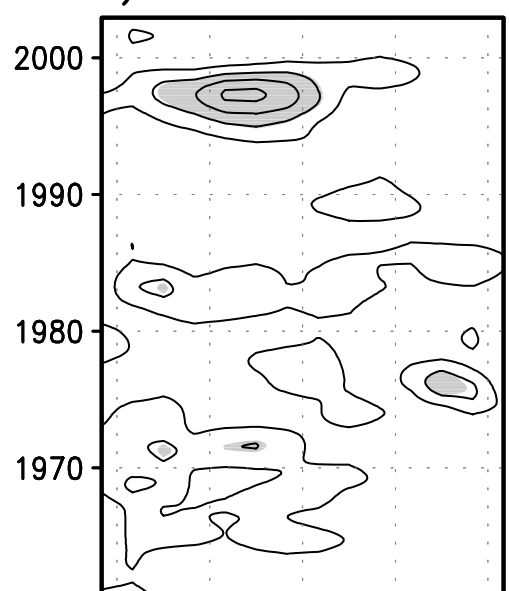

$1960 \Rightarrow 00$

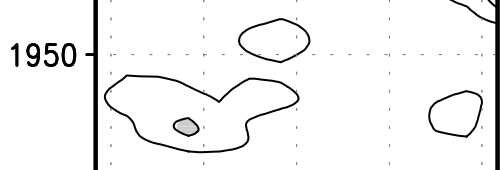

$1940-$

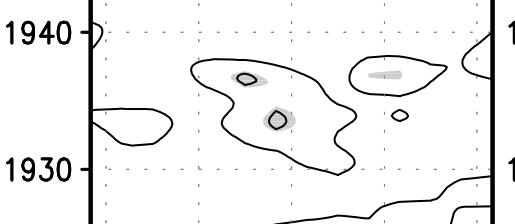

192
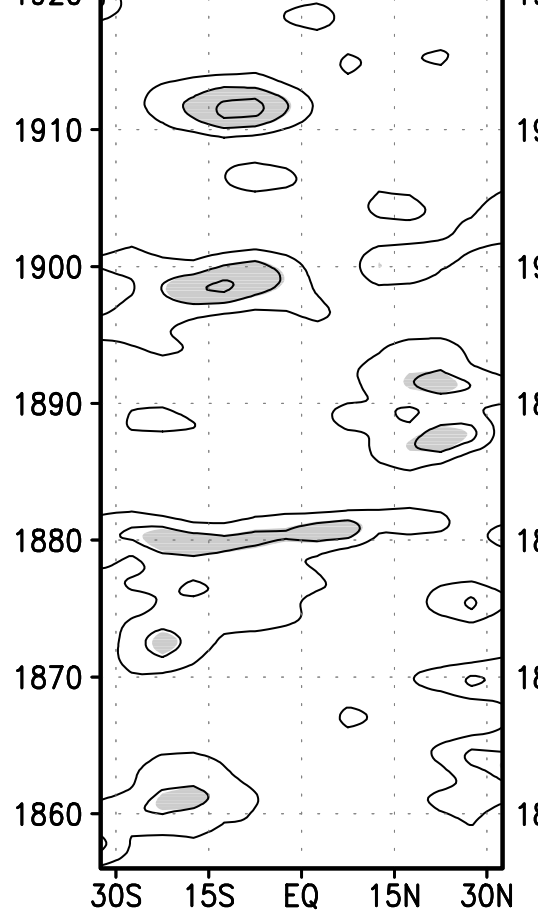

19

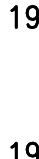

b)

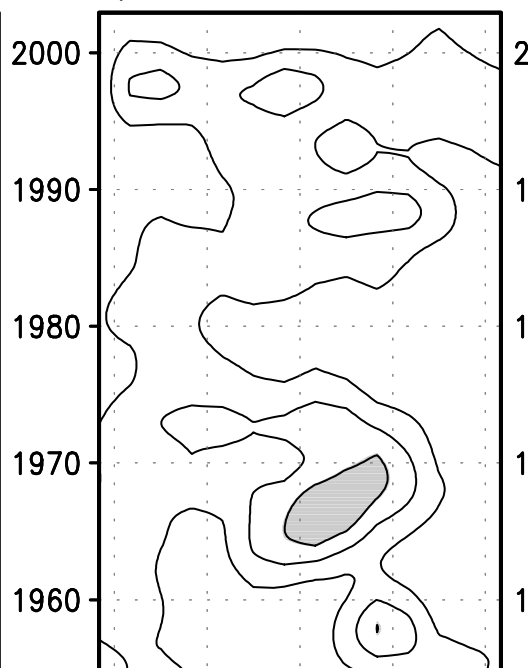

$1950 \bigcirc$

1940
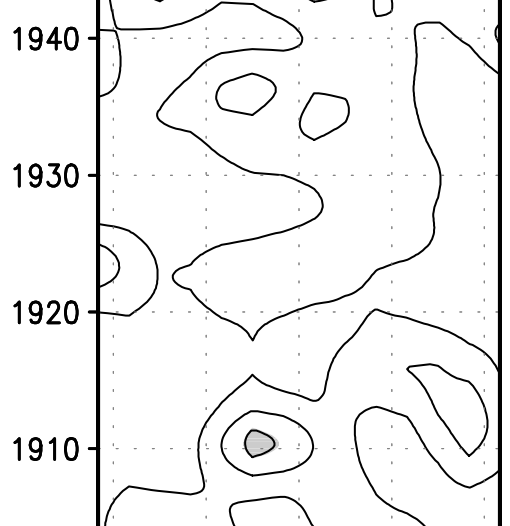

1900

1890

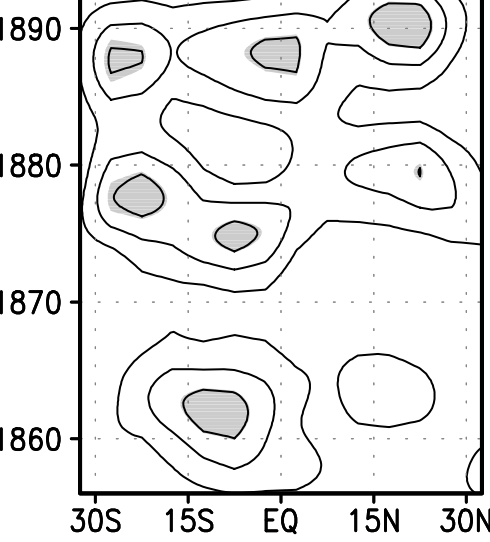

Figure 8 c)

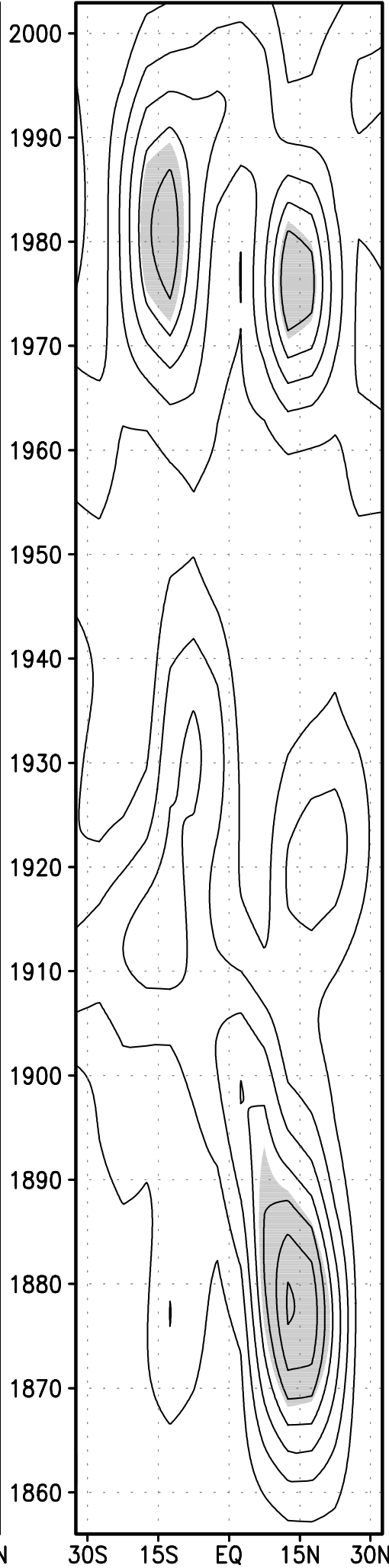

$30 \mathrm{~S} \quad 15 \mathrm{~S} \quad \mathrm{EQ} \quad 15 \mathrm{~N} \quad 30 \mathrm{~N}$ 
anomaly gradient mode) during this time interval. Conversely, for a long time interval between two subsequent abrupt $\Delta \Phi$ reversals of $\pm 180^{\circ}$ (1877-1896, 1896-1949, and 1964-1982), $\Delta \Phi$ oscillates within the intervals associated with the cross-equatorial SST anomaly gradient and monopole modes.

[22] Concerning the 2- to 5-year scale, $\Delta \Phi$ features abrupt reversals of $\pm 180^{\circ}$ in $1870,1896,1917$, and 1957 and gradual and systematic changes from approximately $-180^{\circ}$ to $+180^{\circ}$ during the $1870-1896$ and $1896-1917$ periods (Figure 6). The gradual and systematic $\Delta \Phi$ changes indicate the evolving SST patterns including the dipole-like, crossequatorial SST anomaly gradient and monopole and equatorial patterns for negative and positive $\Delta \Phi$. The varying $\Delta \Phi$ from $-180^{\circ}$ to $-25^{\circ}$ features the dipole-like, crossequatorial SST anomaly gradient and monopole patterns during the 1917-1957 period. The $\Delta \Phi$ changes relatively abruptly from $-180^{\circ}$ to $0^{\circ}$ around the year of 1960 and then oscillates between $-45^{\circ}$ to $+45^{\circ}$ during the 1961-2000 period, when the equatorial and monopole modes were established.

[23] The averaged $\Delta \Phi$ for 8- to 14-year scale smoothes the differences revealed in the averaged $\Delta \Phi$ for the wavelet periods of $8.2,9,9.8,10.7,11.7,12.7$, and 13.9 years (Figure 7 ). The averaged $\Delta \Phi$ for 8.2 years exhibits abrupt reversals of $\pm 180^{\circ}$ in $1904,1911,1944$, and 1982. The averaged $\Delta \Phi$ for 8.2 years remains with values of $+180^{\circ}$ during 1904-1911 and varies from $+90^{\circ}$ to $+180^{\circ}$ during the $1944-1982$ period and from $-180^{\circ}$ to $-90^{\circ}$ during the periods prior to 1904 , from $1911-1944$, and after 1982 . The features of the averaged $\Delta \Phi$ for 8.2 years noted during 1904-1911 are not found for other wavelet periods. Concerning the 9.0-, 9.8-, and 10.7-year scales, the averaged $\Delta \Phi$ shows two abrupt reversals of $\pm 180^{\circ}$, one around the 1940 s to 1950 s $(1948,1951$, and 1954 , respectively) and another by the 1980 s to 1990 s $(1981,1982$, and 1992, respectively) and $\Delta \Phi$ remains close to $+180^{\circ}$ during the periods between the two abrupt reversals and varies from $-180^{\circ}$ to $-90^{\circ}$ prior to the first abrupt $\Delta \Phi$ reversal. The averaged $\Delta \Phi$ series for 11.7 years, 12.7 years, and 13.9 years show only one abrupt reversal of $\pm 180^{\circ}$ and $\Delta \Phi$ varying from $-180^{\circ}$ to $-45^{\circ}\left(+90^{\circ}\right.$ to $\left.+180^{\circ}\right)$ prior to (after) the abrupt $\Delta \Phi$ reversal.

\subsection{Space-Temporal Variability}

[24] Power Hovmöller (time-latitude) diagrams of the SAP series of SST for 1- to 2-year, 2- to 5-year, and 8- to 14-year scales are obtained from the CWT of the zonally averaged SST anomaly time series every $5^{\circ}$ in latitude of the sector $37.5^{\circ} \mathrm{S}-37.5^{\circ} \mathrm{N}$ in the TA (Figure 8). The 1 - to 2 -year diagram evidences every 12-year maxima between the equator and $20^{\circ} \mathrm{S}$ during the $1880-1930$ period, consistent with the previous analysis for the TSA index. In addition, the absence of latitudinal displacements of the 1- to 2-year SAP suggests that the SST variability for short-interannual scale might be modulated by longer scale oscillations.

[25] Significant 2- to 5-year SAP values are found in the equator- $15^{\circ} \mathrm{S}$ and $15^{\circ} \mathrm{N}$-equator bands, respectively, during the 1856-1865 and 1960-1970 periods and in several centers of the $30^{\circ} \mathrm{N}-30^{\circ} \mathrm{S}$ sector during $1875-1895$ (Figure 8). In contrast, the smallest 2- to 5-year SAP values occur for most of the TA during 1900-1950, a period when the Southern Oscillation was weak [Gu and Philander, 1995]. There are also apparent displacements of the significant 2- to 5-year SAP values from the equator to $15^{\circ} \mathrm{N}$ during $1887-1890$ and $1960-1970$, from $5^{\circ} \mathrm{S}$ to $15^{\circ} \mathrm{S}$ during $1860-1865$ and from the equator to $20^{\circ} \mathrm{S}$ during $1875-1880$.

[26] Significant 8- to 14-year SAP values are centered at $15^{\circ} \mathrm{N}$ during $1865-1890$ and in both sides of the TA during 1970-1990 (Figure 8). The significant 8- to 14-year SAP values clearly displace from $15^{\circ} \mathrm{N}$ to equator during $1865-$ 1910. Another aspect that can be inferred from the 8- to 14-year diagram concerns the modulations among SST variability of different scales. The relatively long time intervals of the occurrences of the largest SAP values for the TNA (1875 and 1975) and TSA (1915, which is significant at $10 \%$ level, and 1980) suggest modulations of the decadal SST variability in both sides of the TA by longer scale SST variability.

[27] Meridional propagations of the SST anomalies are further explored by reconstructing them for 1- to 2-year, 2- to 5-year, and 8- to 14-year scales, from the CWT of the zonally averaged SST time series every $5^{\circ}$ in latitude of the sector $37.5^{\circ} \mathrm{S}-37.5^{\circ} \mathrm{N}$ in the TA and using the equation (29) of TC98. These reconstructed SST anomalies are displayed in Hovmöller (time-latitude) diagrams. The diagrams for 1- to 2-year and 2- to 5-year scales illustrate only part of the entire period.

[28] The 1- to 2-year reconstructed SST anomalies propagate dominantly northward from the TSA and EQA latitudes to $15^{\circ} \mathrm{N}$ for some periods alternated by others without apparent propagations and quite reduced SST anomalies (Figure 9). Northward propagations are conspicuous during the 1945-1948, 1957-1961, 1970-1972, $1975-1980,1982-1985$, and $1996-1998$ periods. In addition, it is also apparent that the 1- to 2-year SST anomalies propagate from $30^{\circ} \mathrm{N}$ to $15^{\circ} \mathrm{N}$ during $1952-1957$ and 1982-1985. These results are coherent with propagating aspects of the short-interannual SST anomalies in the TA previously documented [Kayano and Andreoli, 2003]. It is interesting to note, in some cases, that the periods with reduced 1- to 2-year SST anomalies include the abrupt $\Delta \Phi$ reversals of approximately $\pm 180^{\circ}$ for 1 - to 2-year scale. These are the cases of abrupt $\Delta \Phi$ reversals of 1949, 1953, 1962, 1989, and 1990 (Figure 6).

[29] Meridional propagations of the 2- to 5-year reconstructed SST anomalies are apparent within given latitudinal bands and during certain periods alternated by periods with reduced SST anomalies (Figure 9). Indeed, the SST anomalies in the TNA and TSA propagate equatorward with the largest anomalies remaining in the TSA latitudes during $1860-1865$ and $1885-1890$, from $20^{\circ} \mathrm{S}$ to $20^{\circ} \mathrm{N}$ during 1875-1880 while after 1890 propagating features are less pronounced. Similarly to the previous analyses for 1 - to 2-year scale, the periods with reduced 2- to 5-year SST

Figure 8. Hovmöller diagrams of the scale averaged wavelet power for (a) short-interannual, (b) interannual, and (c) decadal scales. The contour intervals are of 0.2 variance units for Figures $8 \mathrm{a}$ and $8 \mathrm{~b}$ and of 0.05 variance units for Figure $8 \mathrm{c}$. Shaded areas are significant at the $95 \%$ confidence level. 
a)

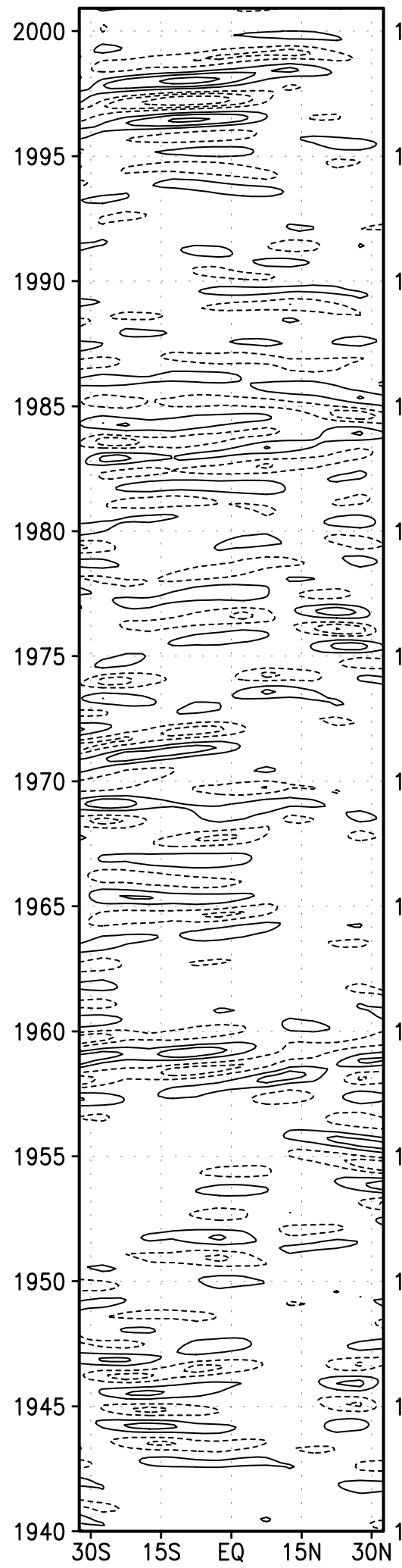

b)

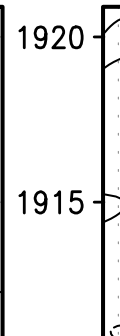

1910

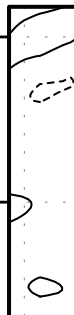

$-$

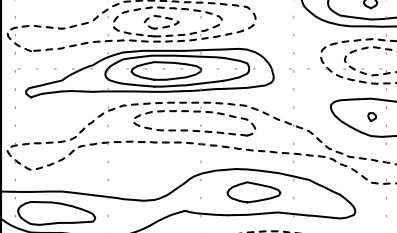

1905

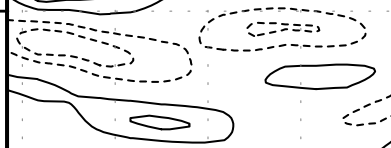

1900

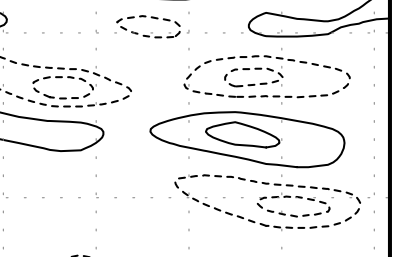

885

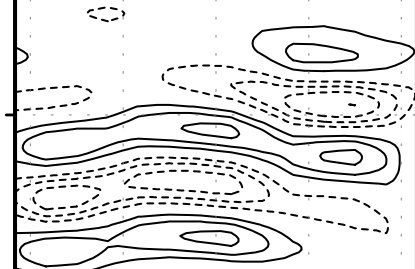

-
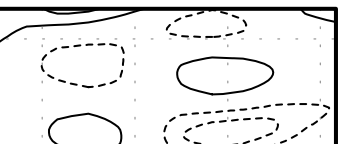

0 $\longrightarrow$ o

其: 0

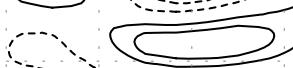

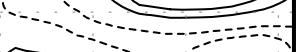
1970

1960

c)

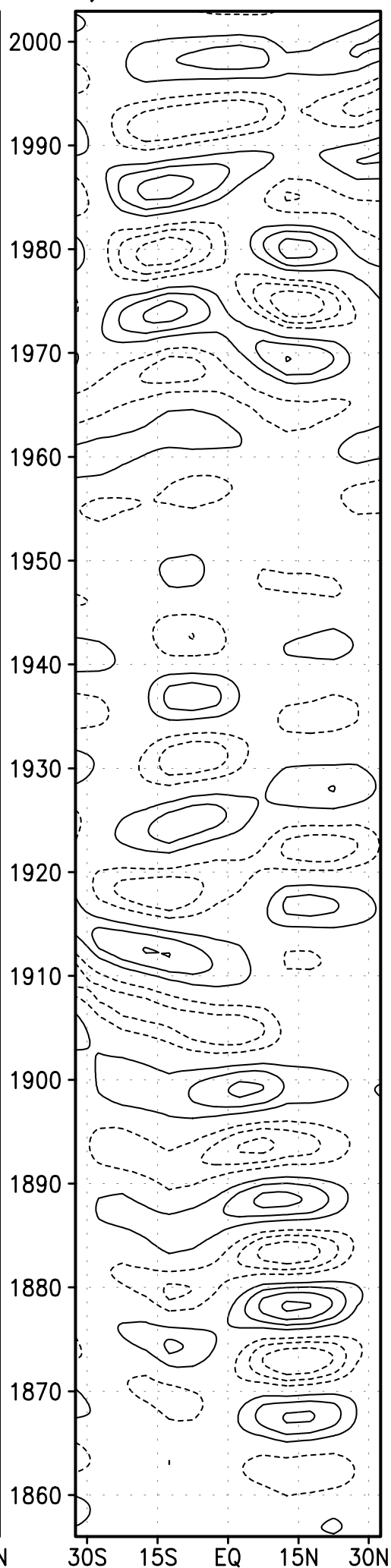

Figure 9. Hovmöller diagrams of the reconstructed standardized SST anomalies averaged for (a) shortinterannual, (b) interannual, and (c) decadal scales. The contour interval is 0.1 . Negative (positive) contours are dashed (continuous), and the zero contour is omitted. 
anomalies include abrupt $\Delta \Phi$ reversals of approximately $\pm 180^{\circ}$ (1870 and 1895) for this scale (Figure 6).

[30] The decadal reconstructed SST anomalies in the $15^{\circ} \mathrm{N}-15^{\circ} \mathrm{S}$ sector show northward propagations during 1870-1900, 1920-1935, and 1985-2000 and southward propagations during 1900-1910 and 1965-1980 (Figure 9). This result reinforces Andreoli and Kayano [2003] findings on the propagating features of the decadal SST anomalies obtained from the extended EOF (EEOF) analysis. Their first and third modes show, respectively, northward and southward propagations of the SST anomalies in the $15^{\circ} \mathrm{N}-15^{\circ} \mathrm{S}$ sector. Comparisons of the Hovmöller diagram of the 8- to 14-year SST anomalies and the averaged $\Delta \Phi$ series for 8.2, 9, $9.8,10.7,11.7,12.7$, and 13.9 years (Figure 7) show clearly that the abrupt $\Delta \Phi$ reversals of approximately $\pm 180^{\circ}$ occur during the periods with change in the meridional propagation directions of the SST anomalies (1904 and around 1981) or with reduced SST anomalies, such as during the 1940-1960 period.

\section{Concluding Remarks}

[31] One-hundred-and-forty-five years (1856-2000) of monthly sea surface temperature (SST) records are used to study the multi-scale variability of the SST in the Tropical Atlantic (TA). Continuous Wavelet Transform (CWT) of indices representing the SST variations in the Tropical North Atlantic (TNA), Tropical South Atlantic (TSA), and Equatorial Atlantic (EQA) is used for time-frequency analyses. Relations of the SST variability on the TNA and TSA are investigated from the CWT of the difference index (TNSD) between the TNA and TSA indices and the cross-wavelet spectrum for the TNA and TSA indices. Meridional propagations of the reconstructed SST anomalies from CWT of zonally averaged SST time series every $5^{\circ}$ in latitude are also investigated. The analyses focus the short-interannual ( $1-2$ years), interannual ( $2-5$ years), and decadal (8-14 years) scales.

[32] The Global Wavelet Power (GWP) of the TNA, TSA, and EQA indices confirm previous findings on the dominant scales of the SST variability in different TA sectors. Indeed, the dominant decadal peaks at 9.8 years and 12.7 years are found for the TNA and TSA indices, respectively, and a non-significant peak at 12.7 years for the EQA index. This result is in agreement with Mélice and Servain [2003], who found separated SST modes in the TNA and TSA with strong decadal component of distinct periodicity (9.6 years and 14 years). In addition, the present analyses showed stronger decadal component of the SST variability in the TSA than in the TNA, in agreement with Mehta and Delworth's [1995] findings. On the other hand, the interannual peaks are significant for the EQA index and non-significant for the TNA and TSA indices. This result reinforces that the interannual component of the TA SST variability lies mainly in the equatorial domain and features an equatorial coupled mode described by Zebiak [1993] and Wagner and da Silva [1994].

[33] The assertion on the independent SST variability in both sides of the TA suggested in several previous papers [Enfield and Mayer, 1997; Enfield et al., 1999; Houghton and Tourre, 1992; Rajagopalan et al., 1998] is confirmed further. In fact, the significant variances of the TNSD index, in general, have correspondence to the significant variances of either the TNA index or TSA index, but not to both indices (Figures 1a, 2a, and 4a). Exception to this is noted during 1970-1985 when significant decadal variances occur for the TNA and TSA indices. The simultaneous occurrences of significant variances for the TNSD, TNA, and TSA indices during 1970-1985 do not necessarily imply in the establishment of a dipole-like pattern or the dynamical connections between the TNA and TSA. This aspect is analyzed using the phase difference between the TNA and TSA indices $(\Delta \Phi)$.

[34] The most interesting aspects of the SST variability in the TA revealed in the present work are related to the $\Delta \Phi$ reversals of $\pm 180^{\circ}$ and the meridional propagations of the reconstructed SST anomalies. Scale-averaged $\Delta \Phi$ series for all scales feature a number of abrupt reversals of $\pm 180^{\circ}$ that depends on the scale, being larger as the scale is smaller. The $\Delta \Phi$ during the period between two subsequent abrupt reversals remains close to $\pm 180^{\circ}$ or varies within subintervals of the $-180^{\circ}$ to $+180^{\circ}$ range; thus the dipole-like, cross-equatorial SST anomaly gradient and monopole and equatorial patterns (all or some of them) are established as part of the evolving feature of SST variability in the TA. It is recalling that, as dipole-like pattern establishes for $\Delta \Phi=$ $\pm 180^{\circ}$, this pattern occurs quite seldom (at the $\Delta \Phi$ abrupt reversal of $\pm 180^{\circ}$ ) as a result of distinct fluctuations in the TNA and TSA.

[35] A very interesting aspect noted for all scales is that the periods of abrupt $\Delta \Phi$ reversals of approximately $\pm 180^{\circ}$ occur within the periods with change in the meridional propagation directions of the SST anomalies or with reduced SST anomalies. This result strongly suggests that the establishment of the SST anomaly patterns in the TA depends crucially on the meridional propagation of the SST anomalies. This aspect of the SST variability in the TA was not documented before.

[36] Acknowledgments. The authors are grateful to the two anonymous reviewers for their useful comments and suggestions. The authors were partially supported by the Conselho Nacional de Desenvolvimento Científico and Tecnológico of Brazil. Wavelet software was provided by C. Torrence and G. Compo and is available at http://paos.colorado.edu/ research/wavelets.

\section{References}

Andreoli, R. V., and M. T. Kayano (2003), Evolution of the equatorial and dipole modes of the sea surface temperature in the tropical Atlantic at decadal scale, Meteorol. Atmos. Phys., 83, 277-285.

Dommenget, D., and M. Latif (2000), Interannual to decadal variability in the tropical Atlantic, J. Clim., 13, 777-792.

Enfield, D. B., and D. A. Mayer (1997), Tropical Atlantic sea surface temperature variability and its relation to El Niño-Southern Oscillation, J. Geophys. Res., 102, 929-945.

Enfield, D. B., A. M. Mestas-Nuñez, D. A. Mayer, and L. Cid-Serrano (1999), How ubiquitous is the dipole relationship in tropical Atlantic sea surface temperature?, J. Geophys. Res., 104, 7841-7848.

Gu, D., and S. G. H. Philander (1995), Secular changes of annual and interannual variability in the tropics during the past century, J. Clim., $8,864-876$

Hastenrath, S. (1978), On modes of tropical circulation and climate anomalies, J. Atmos. Sci., 35, 2222-2231.

Houghton, R. W., and Y. M. Tourre (1992), Characteristics of low-frequency sea surface temperature fluctuations in the tropical Atlantic, J. Clim., 5, 765-771.

Kaplan, A., M. R. Cane, Y. Kushnir, A. C. Clement, M. B. Blumenthal, and B. Rajagopalan (1997), Analyses of global sea surface temperature 1856-1991, J. Geophys. Res., 102, 27,835-27,860. 
Kayano, M. T., and R. V. Andreoli (2003), Propagation of the sea-surface temperature anomalies in the tropical Atlantic, Meteorol. Atmos. Phys., $84,275-284$

Mehta, V. M. (1998), Variability of the tropical Ocean surface temperatures at decadal-multidecadal timescales: I. The Atlantic Ocean, J. Clim., 11, $2351-2375$

Mehta, V. M., and T. Delworth (1995), Decadal variability of the tropical Atlantic Ocean surface temperature in shipboard measurements and in a global ocean-atmosphere model, J. Clim., 8, 172-190.

Mélice, J.-L., and J. Servain (2003), The tropical Atlantic meridional SST gradient index and its relationships with the SOI, NAO and Southern Ocean, Clim. Dyn., 20, 447-464.

Moura, A. D., and J. Shukla (1981), On the dynamics of droughts in northeast Brazil: Observations, theory and numerical experiments with a general circulation model, J. Atmos. Sci., 38, 2653-2675.

Nobre, P., and J. Shukla (1996), Variations of sea surface temperature, wind stress and rainfall over the Tropical Atlantic and South America, J. Clim., 9, 2464-2479.

Rajagopalan, B., Y. Kushnir, and Y. M. Tourre (1998), Observed decadal midlatitude and tropical Atlantic climate variability, Geophys. Res. Lett., $25,3967-3970$
Saravanan, R., and P. Chang (2000), Interaction between tropical Atlantic variability and El Niño-Southern Oscillation, J. Clim., 13, 2177-2194.

Torrence, C., and G. P. Compo (1998), A practical guide to wavelet analysis, Bull. Am. Meteorol. Soc., 79, 61-78.

Torrence, C., and P. J. Webster (1999), Interdecadal changes in the ENSOmonsoon system, J. Clim., 12, 2679-2690.

Wagner, R. G., and A. M. da Silva (1994), Surface conditions associated with anomalous rainfall in the Guinea coastal region, Int. J. Climatol., 14, $179-199$.

Weare, B. C. (1977), Empirical orthogonal analysis of Atlantic Ocean surface temperatures, Q. J. R. Meteorol. Soc., 103, 467-478.

Zebiak, S. E. (1993), Air-sea interaction in the equatorial Atlantic region, J. Clim., 6, 1567-1586.

R. V. Andreoli and M. T. Kayano, Centro de Previsão do Tempo e Estudos Climáticos, Instituto Nacional de Pesquisas Espaciais, Av. dos Astronautas, 1758, 12227-010 São José dos Campos, SP, Brazil. (valeria@cptec.inpe.br; mary@cptec.inpe.br) 